\section{An Improved Cæsium Frequency and Time Standard}

Preliminary measurements have been completed with the longer and more precise standard mentioned at the conclusion of our earlier work ${ }^{1}$. The beam chamber, including the diffusion pump, is $5 \cdot 2 \mathrm{~m}$. long and the distance between the cavity resonators in which the transitions are excited is $2 \cdot 77 \mathrm{~m}$. The width of the resonance curve is $52 \mathrm{c} . / \mathrm{s}$. and at the resonance frequency of approximately $9,200 \mathrm{Mc} . / \mathrm{s}$. this corresponds to a $Q$ factor of $1.8 \times 10^{8}$. The theoretical line width is $55 \mathrm{c}$./s., given by the formula $\Delta F^{\prime}=0.65 \alpha / L$, where $\alpha$ is the most probable velocity of the atoms and $L$ is the distance between the cavities. The difference between the experimental and theoretical values could easily be due to some velocity selection. The resonance curve is reproduced in Fig. 1, in which the experimental points are individual measurements. They illustrate the steadiness of the conditions and the signal-to-noise ratio. The pressure was $3 \times 10^{-7} \mathrm{~mm}$. mercury, and was obtained after 2 days pumping with a 9 -in. 3 -stage fractionating oil-diffusion pump, and with the help of liquid-nitrogen traps.

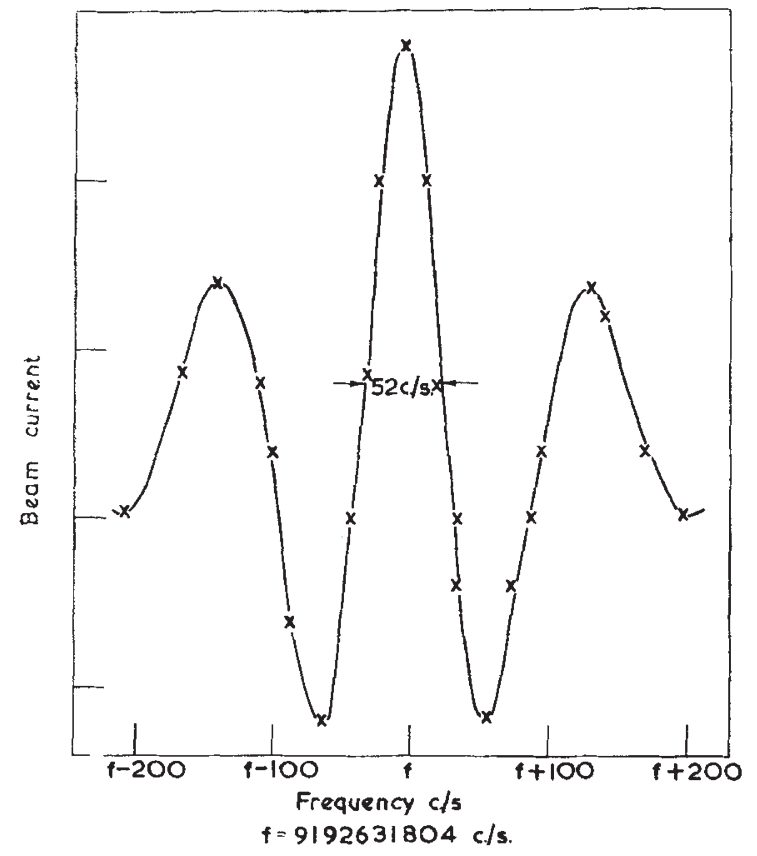

Fig. 1. Experimental resonance curve

The frequency of the peak is $9192631804 \mathrm{c.} / \mathrm{s}$., where the "second" is 9192631770 cycles of the cresium $F, m \quad(3,0) \leftrightarrow F, m, \quad(4,0)$ transition at zero ficld ${ }^{2}$. The field was rather large and non-uniform, and it is estimated that the calculation of the field correction under these conditions can only be made to \pm 2 parts in $10^{10}$. The correction obtained is $32 \mathrm{c} . / \mathrm{s}$. and the new standard thus confirms the value already adopted within the experimental limits. A new magnetic screen is being made to give a small uniform field, and it is expected that the amplitude of the sional can also be increased. The purpose of the present communication is simply to indicate that a standard having a precision of a few parts in $10^{11}$ is quite practicable.
The general features of the design were prepared by Mr. J. V. L. Parry and the instrument was made in the Standards Division Workshop from drawings prepared by Mr. D. C. Barnes. The standard has been put into operation by Dr. L. Essen and Mr. D. E. Sutcliffe has assisted with the experimental work. The work has been carried out as part of the research programme of the National Physical Laboratory and this communication is published by permission of the Director of the Laboratory.

National Physical Laboratory L. Essen, Teddington, Middlesex.

\section{J. V. L. PARRY}

United Kingdom Atomic Energy Authority, Capenhurst, Near Chester. Sept. 22. 1 Essen, L., and Parry, J. V. L., Phil. Trans. Roy. Soc. A, 250, 45 (1957),
2 Markowitz, W., Hall, R. G., Essen, L., and Y'arry, J. V. L., Phys. Rev. Letters, 1, 105 (1958).

\section{MEIE JROLOGY}

\section{Potassium/Sodium Ratio in Rainwater}

IN a recent article Dr. A. T. Wilson' notes that 'the potassium/sodium ratio in rainwater is often larger by a factor of 10 than that in the sea-the obvious source'. His explanation is that most of the sea water transferred to the atmosphere in the form of spray is derived from a very thin surface layer of the sea, which is rich in potassium and nitrogen as a result of the activities of micro-organisms.

Low values of sodium/potassium ratio (to put it in a more convenient form) in rain water are commonly recorded in Europe and the United States, but it seems very unlikely that, in these regions, they are caused in the manner suggested. For, in fact, they are scarcely ever obsərved at exposed coastal stations. The more maritime the situation of a station is, the more closely does the ratio approximate to that of sea water in bulk, that is, 27. Lerwick, in the Shetland Islands, is the most completely exposed station in Europe, and there the ratio has averaged 24 during the 17 months for which records are available, and has never fallen below 18. Really low values invariably occur inland.

The decline in the ratio with increasing distance from the sea is surprisingly rapid, and even in southern Sweden, at places less than $200 \mathrm{~km}$. from the sea, its value is no more than $1 \cdot 7^{2}$. This seems to be as low as it goes: Larsson and Hettick ${ }^{3}$ found that it averaged 1.8 at Illinois in the heart of the United States. It seems a reasonable inference that the direct influence of the sea is confined to quite a narrow coastal belt. Inland, the majority of the sodium and potassium brought down by rain is in all probability derived partly from the combustion of fuels and partly from the land itself. No doubt this is true of other elements also, and it is a point which needs to be borne in mind when assessing the agricultural value of the mineral content of rain water.

\section{B. C. V. ODdIE}

\section{Meteorological Office,}

Air Ministry,

Kingsway,

London, W.C.2. 